\title{
Experimental turbine VT-400
}

\author{
Zitek Pavel $^{1, a}$, Petr Milčák ${ }^{2}$, Noga Tomáš ${ }^{1}$ \\ ${ }^{1}$ UWB in Pilsen, Department of Power System Engineering, Univerzitni 8, 30614 Pilsen, Czech Republic \\ ${ }^{2}$ Doosan Škoda Power, Tylova 1/57, 30100 Pilsen, Czech Republic
}

\begin{abstract}
The experimental air turbine VT400 is located in hall laboratories of the Department of Power System Engineering. It is a single-stage air turbine located in the suction of the compressor. It is able to solve various problems concerning the construction solution of turbine stages. The content of the article will deal mainly with the description of measurements on this turbine. The up-to-now research on this test rig will be briefly mentioned, too, as well as the description of the ongoing reconstruction.
\end{abstract}

\section{Introduction}

Research of flow through the flowpath of a steam turbine is highly important for increasing efficiency and reliability of a blading machine of this type. In general, it can be implemented by various ways.

The most suitable would be to carry out the research on real steam turbines in power plants. However, possibilities of such experiments are quite limited; usually there are extended guarantee tests providing the basic capacity data.

The second option is to measure on experimental research steam turbines in laboratories of their producers. Their construction currently enables more detailed measurements of performance characteristics. Yet, operation of these test rigs is fairly expensive, and operational parameters often do not provide the option of more detailed measurement inside a flow part.

Air turbine models located at specialized sites are the last option of experimental research. A construction of these turbines allows to inspect flow fields in various operational modes, and to compare results with a design state. Nevertheless, when we want to obtain such detailed data, it brings about a necessary issue of how to apply the results directly on real machines (geometrical and physical similarity).

\section{Description of the experimental device}

It is a single-stage air turbine located in the compressor suction. The turbine is a model of a highpressure part of a steam turbine in the scale of 1:2. This layout provides, apart from almost constant air input parameters, also an easy access to the turbine and its measuring points. The scheme of the experimental loop is on figure 1 , whereas figure 2 shows the whole device.

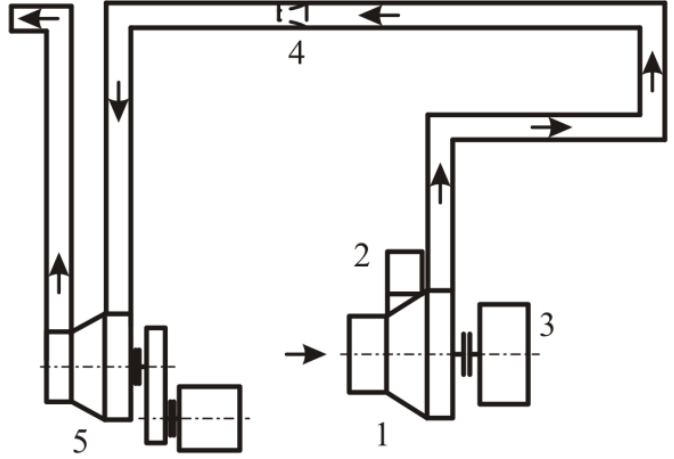

Figure 1 Scheme of experimental line

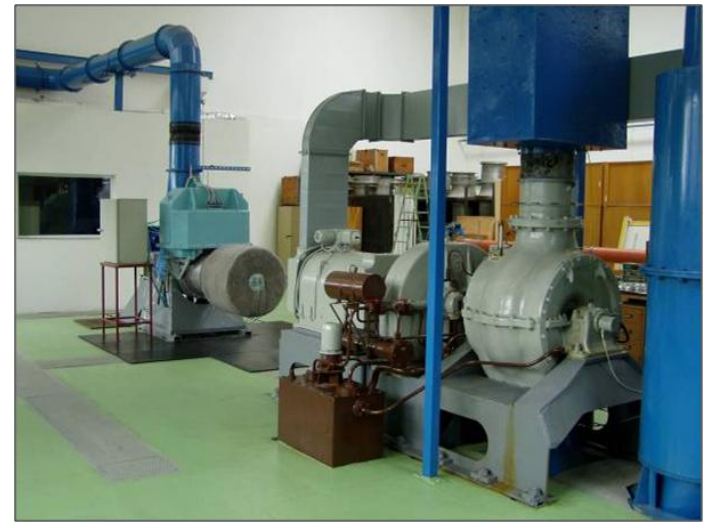

Figure 2 Experimental device

As apparent from the scheme, the rig consists of 5 main parts in total. The base is the turbine VT400 of a disc construction without a shaft gland (marked as No. 1 on the scheme). Various problems concerning turbine stages constructional solution are possible to solve on the air turbine. A hub diameter is $400 \mathrm{~mm}$, the largest blade is $47 \mathrm{~mm}$ long. Maximum speed is $40001 / \mathrm{min}$. A turbine section can be viewed on figure 3 .

\footnotetext{
${ }^{a}$ Corresponding author: zitek@kke.zcu.cz
} 


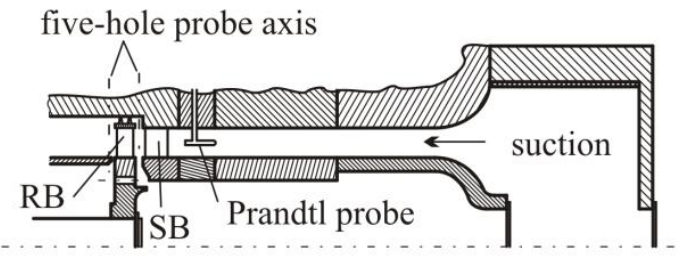

Figure 3 Section of experimental turbine

The second device of the experimental rig is a traversing device, marked as No. 2 on figure 1. The traverser enables the pneumatic probe to shift radially (under the hub as well as above the tip), peripherally (over two spacings of stationary blades), and also its automatic flow-wise turn. It allows a thorough measuring of the flow field behind both stationary and moving blades. A five-hole pneumatic probe, designed specially for this purpose, is used for such measurements on the air turbine. The probe is $700 \mathrm{~mm}$ long, and the holder diameter is $10 \mathrm{~mm}$. The end piece of the probe is adjusted in such a manner, that it has minimum influence on the flow, and the probe sensor is placed in its rotating axis (see the model on figure 4)

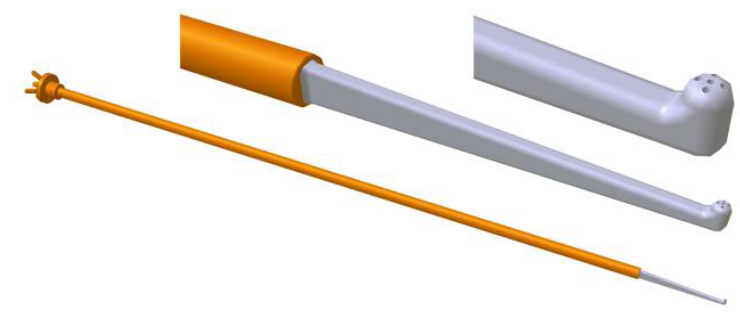

Figure 4 Model of 5-hole probe

The number three on the scheme represents a dynamometer, which provides information on speed and the moment of torsion, and at the same time, it keeps one of those values constant. It is a product of MEZ Vsetín; its maximum speed is $50001 / \mathrm{min}$. and maximum capacity $150 \mathrm{~kW}$.

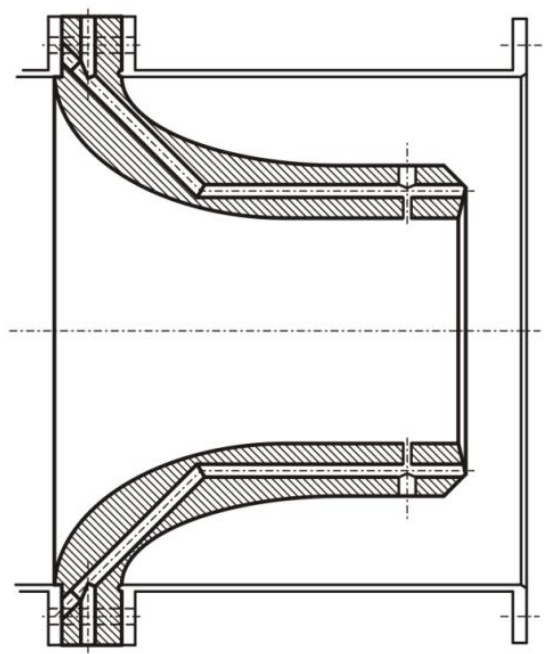

Figure 5 Nozzle for flow rate measurement

Another part of the rig is a nozzle for measuring the air flow (figure 1 number 4). The nozzle was made according to the ASME norm; the nozzle section is on figure 5 .

A radial single-stage compressor represents the last part of the experimental loop (see No. 5 on figure 1). Minimum speed of the compressor is $18501 / \mathrm{min}$, and maximum pressure drop, which can be reached on the turbine due to the compressor, is $6500 \mathrm{~Pa}$.

\section{Measurements}

In the past, the turbine served, for instance, to determine the influence of partial admission on the stage efficiency. Since 2000 , the research has been focused mainly on the influence of blade shaping on the stage efficiency [1], [2], [3], [4].

Currently, the testing of the experimental turbine VT400 stages consists of two parts - measuring integral characteristics and stationary measurements of flow fields behind stationary (SB) and moving blades (MB).

The purpose of integral characteristics measurements is to obtain the efficiency dependence on the ratio $\mathrm{u} / \mathrm{c}$. A change of pressure drop on the stage appears during this measurement at constant turbine speed. Due to the experimental device, the inlet pressure in front of the turbine is determined by the atmospheric pressure, and thus only outlet pressure and pressure drop on the stage can be measured. Pressure drop can be changed by the compressor performance, or more precisely, by the performance of the engine which powers the compressor. Changes are made in steps and manually, which complicates to set up a certain required mode and maintain a constant state. It is also possible to change the velocity ratio $\mathrm{u} / \mathrm{c}$ by a change in the turbine speed at the constant pressure drop.

Apart from speed, moment of torsion and pressure drop, the flow rate and several static pressures at the hub and the tip in front of and behind the stage are measured as well. There are also pressure extractions at the outlet from SB (figure 6), which provide information regarding the size of the hub and tip reaction. Inlet and outlet velocities are calculated from the measured mass flow and the continuity equation. The total states in front of and behind are calculated from velocities and measured static pressures on walls.

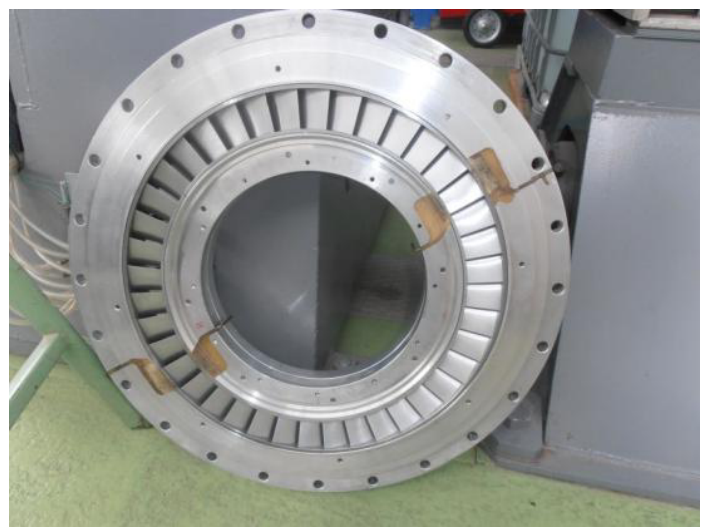

Figure 6 Static pressured extractions at SB

Flow fields stationary measurements behind both stationary (SB) and moving blades (MB) grant very 
important information on flow in the stage. They provide pressure, or rather, velocity image of a flow field, and distribution of several variables along the blade height, after suitable peripheral data averaging, which is very valuable for designers. It is not only about loss values, but also velocities, in other words, angles to calculate deviations and flow incidences; furthermore e.g. reaction distribution and flow rate etc. Such data provide substantial information on behavior and influence of various shape modifications of blades or influence of offdesign operation, when compared with theoretical design.

Flow fields measurement (wake traversing) takes place at a selected operational mode (pressure drop and ratio $\mathrm{u} / \mathrm{c}$ ), which is preserved at the constant value within the tunnel possibilities. It is measured by a five-hole pneumatic probe (figure 7) of the size of approximately $4 \mathrm{~mm}$, which represents roughly $9 \%$ of the blade height. Data acquired by this can be partially distorted. Due to the probe size (and its holder), the axial gap between SB and $\mathrm{MB}$ was extended. The probe is fixed in the traversing device. It can be manually shifted in two positions - for measuring behind SB or MB.

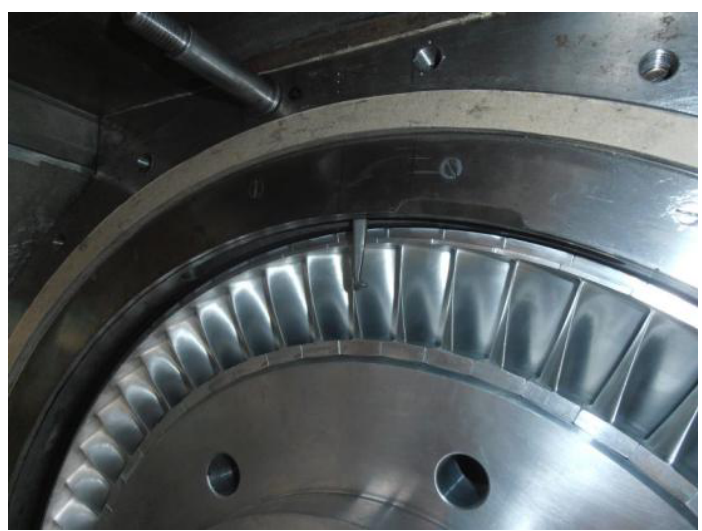

Figure 7 A 5-hole probe detail

Apart from static pressures and pressures from a fivehole probe, we can measure the velocity profile at the inlet into the stage using the Prandtl probe. We receive values of speed and moments of torsion from the dynamometer. Moreover, we measure air temperatures to determine the flow rate. We also extract static pressures in front of and behind the nozzle located in the pipeline to determine the flow rate. We use the following procedure to determine the flow rate.

Air density in front of and behind the nozzle is

$$
\begin{aligned}
& \rho_{d 1}=\frac{p_{d 1}}{r_{v} T_{d 1}}\left(1-k_{1} \varphi\right)=\frac{p_{d 1}}{287,139 \cdot T_{2}} \cdot 0,995 \\
& \rho_{d 2}=\frac{p_{d 2}}{r_{v} T_{d 2}}\left(1-k_{1} \varphi\right)=\frac{p_{d 2}}{287,139 \cdot T_{2}} \cdot 0,995
\end{aligned}
$$

where

$$
\begin{array}{ll}
k_{1} \varphi & \text { is a correction on relative air humidity } \\
T_{d 1} & \text { is temperature in front of the nozzle }[\mathrm{K}] \\
r_{v} & \text { is individual gas constant; for air } \\
& \text { is } r_{v}=287,139 \frac{\mathrm{J}}{\mathrm{kgK}}
\end{array}
$$

note.: we consider $T_{2}=T_{d 1}=T_{d 2}$
A ratio of the minimum nozzle section $D_{d M i n}$ and pipeline section $D_{p}$ is

$$
m=\left(\frac{D_{d \text { Min }}}{D_{p}}\right)^{2}=\left(\frac{0,18}{0,4}\right)^{2}=0,2025
$$

Air velocity in the narrowest nozzle section

$$
\begin{gathered}
w_{2}=\frac{1}{\sqrt{1-m^{2} \cdot\left(\frac{p_{d 2}}{p_{d 1}}\right)^{\frac{2}{\kappa}}}} \cdot \\
\sqrt{2 \cdot \frac{\kappa}{\kappa-1} \cdot \frac{p_{1 d}}{\rho_{d 1}} \cdot\left[1-\left(\frac{p_{d 2}}{p_{d 1}}\right)^{\frac{\kappa-1}{\kappa}}\right]}
\end{gathered}
$$

Reynolds number of the nozzle is

$$
R e_{d 2}=\frac{w_{2} \cdot D_{d 2} \cdot \rho_{d 2}}{\mu_{2}}
$$

A substitution of $D_{d 2}=0,18 \mathrm{~m}$ and $\rho_{d 2}$ from the equation (2)

$$
R e_{d 2}=6,269 \cdot 10^{-4} \cdot \frac{p_{d 2}\left(1-k_{1} \varphi\right)}{T_{2} \cdot \mu_{2}} \cdot w_{2}
$$

Nozzle flow coefficient is defined

$$
\alpha=\frac{c_{q}}{\sqrt{1-m^{2}}}
$$

The coefficient $c_{q}$ is independent on $R e_{d 2}$ and equals to 0,996 for values $R e_{d 2}>0,5 \cdot 10^{6}$, which can be practically considered for measuring on the air line. The flow coefficient is $\alpha=1,017$ after a substitution for $m$ in the equation (7).

Expansion coefficient

$$
\begin{aligned}
& \varepsilon=\sqrt{\frac{1-m^{2}}{1-m^{2} \cdot\left(\frac{p_{d 2}}{p_{d 1}}\right)^{\frac{2}{\kappa}}}} . \\
& \sqrt{\frac{1}{1-\frac{p_{d 2}}{p_{d 1}} \cdot \frac{\kappa}{\kappa-1} \cdot\left[\left(\frac{p_{d 2}}{p_{d 1}}\right)^{\frac{2}{\kappa}}-\left(\frac{p_{d 2}}{p_{d 1}}\right)^{\frac{\kappa+1}{\kappa}}\right]}}
\end{aligned}
$$

Air volume

$$
m_{v}=\alpha \cdot \varepsilon \cdot S_{d 2} \cdot \sqrt{2 \cdot \rho_{d 2}\left(p_{d 1}-p_{d 2}\right)},
$$

where

is the nozzle flow coefficient according to (7); $\alpha=1,017$

$\varepsilon$ is expansion coefficient according to (8)

$S_{d 2} \quad$ is the outlet nozzle section; for $D_{d 2}=0,18 \mathrm{~m}$ is $S_{d 2}=0,02543 \mathrm{~m}^{2}$ 


\section{Device modernization}

Currently, the whole device is undergoing a reconstruction, which should be finished soon. The reason for the reconstruction is to increase accuracy and measurement speed, and to expand measurement posibilities. The renovation concerns three parts of the loop.

The first change refers to measurements of flow fields behind stationary and moving blades. The current traverser allows to measure by one probe only, i.e. we can measure either behind stationary or moving rings. The current traverser controlling mechanism is not sufficient either. The control is not fully automatized, the probe shift in a radial direction is possible to be made in a step mode only. The new traverser (model on figure 8) will not only be fully automatized, but it will also enable measuring by two probes simultaneously, i.e. we will measure the flow field both behind $\mathrm{SB}$ and $\mathrm{MB}$ at the same time. Furthermore, the turbine casing will be adapted, and the range of circumferential movement of the probe will be enlarged.

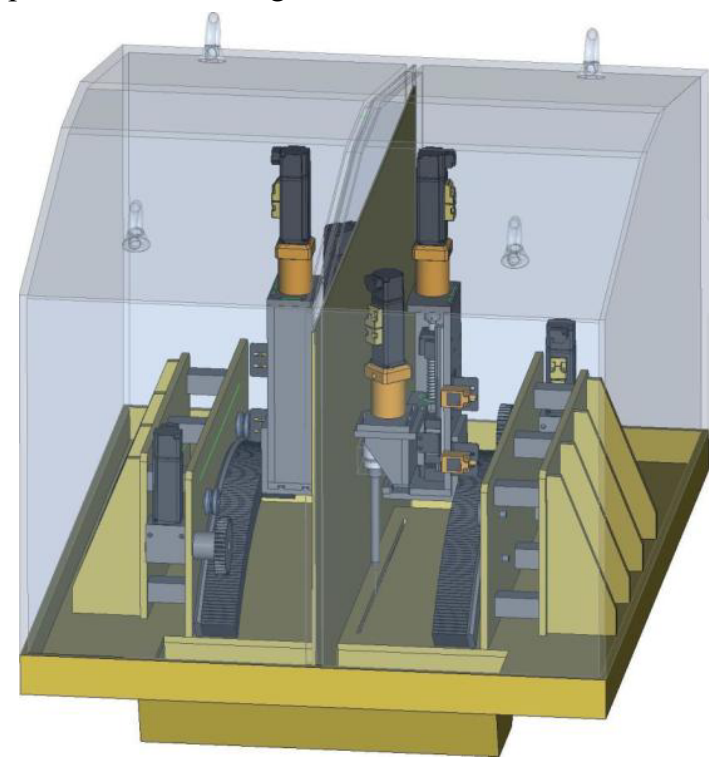

Figure 8 A new traverser model

A purchase of new pneumatic probes is related to the traverser exchange. We will receive two five-hole probes with a head diameter of $1,6 \mathrm{~mm}$ and a frequency response of $0,5 \mathrm{kHz}$. We shall also receive one five-hole probe with a head diameter of $1,6 \mathrm{~mm}$ and a frequency response of $2,0 \mathrm{kHz}$ meant for non-stationary measurement, along with the above mentioned new probes. We will buy new pressure scanners for data collection, not only from those probes, but for static pressure extractions as well. It will result in a growth of velocity and measurement accuracy, and, moreover, we shall be able to measure the pressure at more points at the same time.

The next innovated part will be a source of pressurized air. The technical condition of the current compressor corresponds to the year of its production and is completely insufficient. It does not allow a fluent automatic regulation, but only a step regulation. The compressor also does not enable to measure the pressure drop; it is determined from measuring on the turbine.
The objective of the pressurized air source modernization is to improve the operational stability, and mainly, to enhance the possibility of regulation, including the performance program adaptation. The new compressor performance is required to be up to $50 \mathrm{~kW}$, pressure drop up to $12000 \mathrm{~Pa}$ and flow rate of $2-2,5 \mathrm{~kg} / \mathrm{s}$ (the compressor characteristic on figure 9). The new compressor shall allow both the increase in pressure drop and the connection to the control system of the whole loop; this will allow automatic regulation of the compressor as well as data registration from the compressor.

Pressure increase in $\mathrm{kPa}$

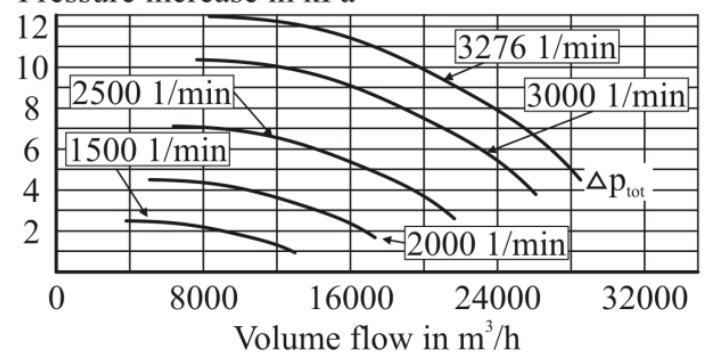

Figure 9 Compressor characteristics

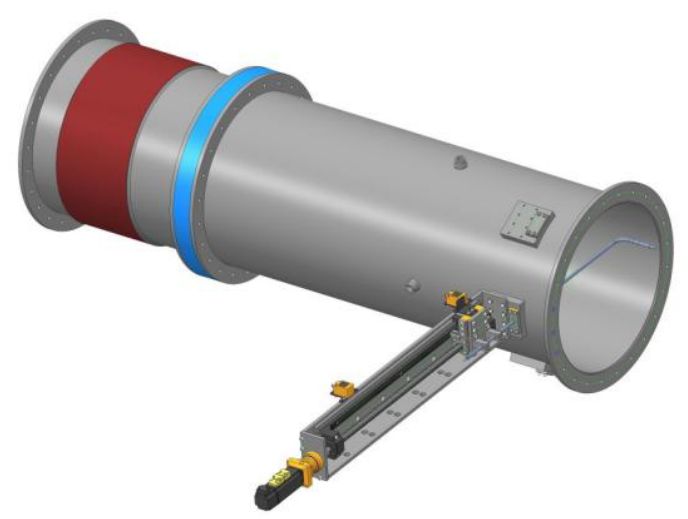

Figure 10 Location of 1D traverser

Another change will appear in defining the air flow rate. Currently, a nozzle located in the pipeline between the turbine and the compressor (see Chapter 3) is used for measuring the flow rate. To know the air temperature is, among others, necessary to analyze the flow. As for now, the air temperature is measured at the turbine outlet, i.e. in a distance of several dozens of meters from the nozzle itself. Also the pressure transducer, which evaluates the pressure extractions from the probe, is currently located several tens of metres from the nozzle, therefore, some inaccuracies in measurements may occur. The temperature sensor and pressure transducer will be newly placed at the point of the flow measurement. In addition, the flow rate measuring will be extended by traversing the velocity profile in the pipeline, near the nozzle by a newly installed 1D traverser, including a new pressure probe, which will allow the nozzle calibration. The 1D traverser model can be viewed on figure 10 . 


\section{Conclusions}

The knowledge of detailed flow flied in the turbine flow component is a necessary condition for a correct blading design. An acquisition of this data is a subject of testing on model air turbines. VT-400 is one of two such turbines in the Czech Republic. The reconstruction of the whole apparatus will allow a continuing research of flowing in the air turbine stage, in cooperation with our industrial partner Doosan Skoda Power.

We would like to continue the research in the $3 \mathrm{D}$ blade shaping influence on the stage efficiency in the future; we intent to study the turbine stage behaviour during off-desing, and we would also like to pursue the inspection of the influence of balancing holes onto the efficiency, or the influence of axial gap flows on hub between moving and stationary rings.

We would also like to concentrate on the air turbine, which has been only slightly affected by the reconstruction. At present, we are exploring options of VT-400 construction adjustments with the objective to change the hub diameter or rings which would extend / shorten the blade length, and thus influence the L/D ratio. Furthermore, we would like to propose such adjustments, which would allow to research the influence of tip seals.

\section{Acknowledgements}

This work has been supported by the SUSEN Project CZ.1.05/2.1.00/03.0108 realized in the framework of the European Regional Development Fund (ERDF) and student project SGS-2014-070 (Zvyšování účinnosti, spolehlivosti a životnosti energetických strojů a zařízení 3).

\section{References}

1. J. Vomela, P. Milčák, The development of highefficiency turbine blades. Cieplne maszyny przeplywowe. Turbomachinery. Lodz : Technical University of Lodz, 2005, 557-564. ISSN 0137-2661

2. P. Milčák, M. Hoznedl, D. Krivánka, Testování turbínového stupně s $3 D$ lopatkováním - úvodní experimenty. Strojárstvo, Mechanical Engineering Journal, 2009, ISSN 1335-2938.

3. P. Milčák, M. Hoznedl, P. Žitek, Comparison of results from experimental testing of three variants of turbine stage with modern $3 D$ blades. In EPJ Web of Conferences. DOI: 10.1051/epjconf/20134501063

4. M. Klimko, D. Okresa, Measuring on the air turbine $V T-400$, in Acta Polytechnica - Journal of Advanced Engineering (to be published). 